\title{
ANALISIS PERBANDINGAN KINERJA KEUANGAN PADA BANK UMUM SYARIAH SEBELUM DAN SESUDAH MELAKUKAN SPIN-OFF (STUDI PADA BANK BTPN SYARIAH)
}

\author{
Zata Ghaisani Mazaya ${ }^{1}$, Rulfah M Daud ${ }^{* 2}$ \\ ${ }^{1,2}$ Program Studi Akuntansi Fakultas Ekonomi dan Bisnis Universitas Syiah Kuala \\ e-mail: zatamazaya@ gmail.com ${ }^{1}$, rulfahm.daud@ unsyiah.ac.id ${ }^{2}$

\section{* Corresponding Author}

\begin{abstract}
Abstrak
This study aims to determine whether there are differences in the performance of Public Islamic Bank (BTPN Syariah) before and after spin-off. The financial ratios used are CAR (Capital Adequancy Ratio), NPF (Non Performing Finance), FDR (Financing to Desposit Ratio), BOPO (Operating Expenses to Operating Income), and ROA (Return On Asset). The research method used in this research is descriptive comparative. Type of data used is secondary data in the form of quarterly financial statement of BTPN Syariah, quarter 12011 until with quarter 3

2014 for data before spin-off and quarter 42014 for data after spin-off. Data analysis was done by using Normality Test and Paired Sample T-Test. Data is processed by using SPSS (Statistical Pakage for Social Science) 25th version. The results of this study showed that at the ratios of BOPO there is no difference between before and after spin-off. While in the ratios of CAR, NPF, FDR and ROA there are difference between before and after spin-off
\end{abstract}

Keywords: $C A R, N P F, F D R, B O P O, R O A$, and Spin-off

\section{Pendahuluan}

Perbankan syariah adalah segala sesuatu yang menyangkut tentang bank syariah dan unit usaha syariah, mencakup kelembagaan, kegiatan usaha, serta cara dan proses dalam melaksanakan kegiatan usahanya. Bank syariah berfungsi menghimpun dana dari masyarakat dalam bentuk titipan dan investasi dari pihak pemilik dana. Fungsi lainnya ialah menyalurkan dana kepada pihak lain yang membutuhkan dana dalam bentuk jual beli maupun kerja sama usaha (Ismail, 2011).

Perbankan merupakan lembaga keuangan terpenting bagi pembangunan suatu negara. Hal ini disebabkan karena fungsi perbankan adalah sebagai lembaga intermediasi keuangan (financial intermediary institution) sebagaimana ditegaskan dalam Pasal 1 Angka 2 Undang-Undang Nomor 10 Tahun 1998 tentang Perubahan Atas UndangUndang Nomor 7 Tahun 1992 yakni bahwa bank adalah badan usaha yang menghimpun dana dari masyarakat dalam bentuk simpanan dan menyalurkan kepada masyarakat dalam bentuk kredit dan/atau bentuk-bentuk lainnya dalam rangka meningkatkan taraf hidup rakyat banyak (Umam, 2015).
Kebijakan deregulasi sektor keuangan pada 27 Oktober 1988 telah memberikan perubahan yang fundamental dalam sistem perbankan Indonesia, dan berlanjut pada tahun 1992 dengan dikeluarkannya Undang-Undang Nomor 7 tahun 1992 tentang bank syariah yang diperbolehkan beroperasi di Indonesia dengan menerapkan sistem bagi hasil. Kemudian sejak dikeluarkannya Undang-Undang Nomor 10 tahun 1998 yang memperkuat UndangUndang Nomor 7 Tahun 1992, Indonesia secara de jure telah menerapkan sistem perbankan ganda (dual banking system), yaitu perbankan konvensional dan perbankan syariah dapat beroperasi berdampingan di seluruh wilayah Indonesia (Norfitriani, 2016).

Pada tahun 2008, pemerintah Indonesia membentuk Undang-Undang Nomor 21 Tahun 2008 tentang Perbankan Islam di Indonesia. Tindakan ini difokuskan pada pengaturan oleh industri perbankan syariah di Indonesia. Setelah penerbitan UU ini, ada peningkatan yang signifikan dalam jumlah bank syariah. Salah satu poin penting dalam UU No. 21 Tahun 2008 adalah persyaratan bahwa bank-bank konvensional harus melakukan pemisahan (spin-off) terhadap unit usaha syariah mereka apabila telah 
memenuhi beberapa kriteria sebagai berikut: (1) unit usaha syariah telah mencapai $50 \%$ aset bank induknya; atau (2) telah mencapai 15 tahun setelah UU ini berlaku atau pada tahun 2023.

Spin-off merupakan salah satu upaya yang dapat dilakukan untuk memperbaiki dan memaksimalkan kinerja perusahaan. Dengan memisahkan UUS (Unit Usaha Syariah) yang dimiliki oleh suatu BUK (Bank Umum Konvensional), diharapkan BUK yang dimaksud serta BUS (Bank Umum Syariah) baru yang terbentuk dari hasil spin-off tersebut dapat semakin fokus beroperasi, lebih cepat dan fleksibel dalam pengambilan keputusankeputusan bisnis, serta kebijakan untuk perbaikan perusahaan dapat dilakukan lebih tepat guna (Nizar, 2015).

Kebijakan spin-off adalah salah satu strategi yang ditempuh oleh regulator untuk mempercepat pertumbuhan dan kinerja bank syariah. Untuk membuktikan apakah bank yang melakukan spin-off semakin membaik, maka perlu dilakukan analisis terhadap kinerja keuangan bank hasil spin-off tersebut. Kinerja keuangan dilakukan untuk melihat sejauh mana perusahaan telah melaksanakan aturan-aturan pelaksanaan keuangan secara baik dan benar yang dianalisis dengan alat-alat analisis keuangan, sehingga dapat diketahui mengenai baik buruknya keadaan keuangan suatu perusahaan yang mencerminkan prestasi kerja dalam periode tertentu. Hal ini sangat penting agar sumber daya digunakan secara optimal dalam menghadapi perubahan lingkungan (Fahmi, 2011).

Dalam penelitian ini, rasio keuangan yang digunakan untuk mengukur kinerja keuangan meliputi CAR (Capital Adequancy Ratio), NPF (Non Performing Finance), FDR (Financing to Desposit Ratio), BOPO (Beban Operasional terhadap Pendapatan Operasional), dan ROA (Return On Asset). Adapun alasan penulis memilih rasio tersebut dikarenakan rasio tersebut adalah rasio keuangan utama dimana pengembalian atas aset-aset bank atau profitabilitas bank ditunjukkan oleh rasio ROA. Permodalan perbankan syariah ditunjukkan dari nilai rasio CAR. Kualitas pembiayaan yang disalurkan dan efisiensi operasional perbankan syariah ditunjukkan dari rasio NPF dan rasio BOPO serta tingkat intermediasi ditunjukkan oleh rasio FDR.

Bank Tabungan Pensiunan Nasional Syariah
(BTPN Syariah) adalah BUS ke-12 di Indonesia yang lahir dari proses akuisisi, konversi dan spin-off sekaligus. Bank ini perlu dinilai terutama pada kinerja keuangannya, apakah dengan proses pemisahan (spin- off) dari Bank Induknya, Bank ini lebih efektif meningkatkan kinerja keuangannya atau sebaliknya.

BTPN (Bank Tabungan Pensiunan Negara) Syariah adalah satu-satunya bank yang fokus melayanan segmen tunas usaha rakyat, dengan tujuan memberdayakan jutaan keluarga pra atau cukup sejahtera (merambah bisnis usaha mikro, kecil, dan menengah (UMKM) serta prasejahtra produktif). Bank yang berdiri di Bandung pada 1958 ini memang tidak populer sebab produknya hanya satu yaitu bisnis pensiun. Selain menyediakan akses layanan keuangan kepada masyarakat tersebut, BTPN Syariah juga menyediakan pelatihan keuangan sederhana untuk membantu mata pencaharian nasabahnya agar dapat terus berlanjut serta membina masyarakat yang lebih sehat. (www.btpnsyariah.com)

Mengenai besaran aset ideal yang harus dimiliki UUS agar bisa spin-off, Adiwarman Karim, akademisi dan praktisi ekonomi syariah, berpendapat bahwa UUS yang akan spin-off paling tidak harus memiliki aset sekitar Rp3 triliun sampai dengan Rp10 triliun agar dapat bertahan. Namun Asset BTPN hanya RP10,6 triliun per Desember 2007. Begitu pula kredit dan dana pihak ketiga (DPK)-nya yang saat itu tercatat RP7,85 triliun dan Rp8,80 triliun namun BTPN berani dan mampu untuk melakukan spinoff. (Infobank, 2018:84-85)

Berdasarkan penelitian terdahulu yang dilakukan oleh Chotib dan Utami (2014) menunjukkan bahwa rasio NPF, NPM, ROA, ROE sebelum dan sesudah spin-off tidak berbeda secara signifikan, sedangkan CAR dan FDR ada perbedaan yang signifikan. Penelitian Anggarini, Yuliani dan Umrie (2016) menemukan bahwa tidak terdapat perbedaan signifikan pada CAR dan ROA namun perbedaan signifikan ditemukan pada NPF.

\section{Tinjauan Pustaka \\ Bank Syariah}

Badan usaha yang yang menjalankan seluruh kegiatannya menggunakan prinsip syariah seperti menghimpun dana dari masyarakat dalam bentuk simpanan dan menyalurkannya kepada masyarakat 
dalam bentuk pembiayaan dan atau bentuk lainnya dalam rangka meningkatkan taraf hidup rakyat (Danuprata, 2013).

\section{Konsep Spin-off}

Kebijakan spin-off tertuang dalam UndangUndang Nomor 21 tentang Perbankan Syariah dan dikuatkan dengan adanya Peraturan Bank Indonesia (PBI) No.11/10/PBI/2009 tentang Unit Usaha Syariah (UUS). Dikatakan bahwa UUS wajib dipisahkan (spin-off) dari BUK apabila nilai aset UUS telah mencapai 50 persen dari total nilai aset Bank Umum Konvensional (BUK) induknya, atau paling lambat 15 tahun sejak berlakunya Undang- Undang Nomor 21 Tahun 2008 tentang Perbankan Syariah (Iqbal, 2014:37).

Tujuan dikeluarkannya peraturan ini adalah agar perkembangan perbankan syariah dapat terfokus kepada bank syariah, yakni bank umum syariah (BUS) dan bank pembiayaan rakyat syariah (BPRS) sehingga ke depannya tidak ada lagi unit usaha syariah (UUS). Dengan difokuskannya perkembangan perbankan syariah, diharapkan dapat meningkatkan share perbankan syariah itu sendiri, untuk menjamin terpenuhinya prinsip-prinsip syariah, prinsip kesehatan bank syariah, dan juga diharapkan dapat memobilisasi dana dari negara lain yang mensyaratkan pengaturan terhadap bank syariah diatur dalam undang-undang sendiri.

\section{Kinerja Keuangan}

Kinerja keuangan perusahaan merupakan suatu gambaran mengenai kondisi dan keadaan dari suatu perusahaan yang dianalisis dengan alat-alat analisis keuangan, sehingga dapat diketahui baik atau buruknya kondisi keuangan dan prestasi kerja sebuah perusahaan dalam waktu tertentu. Kinerja keuangan adalah hasil dari banyak keputusan individu yang dibuat secara terus menerus oleh manajemen. Kinerja keuangan merupakan gambaran hasil atau prestasi yang dicapai perusahaan dalam suatu periode tertentu yang menjadi cermin dan tingkat kesehatan perusahaan tersebut (Inayah, 2014).

\section{Rasio Keuangan}

Menurut Van Home (2005:34), rasio keuangan adalah alat yang digunakan untuk menganalisis kondisi keuangan dan kinerja perusahaan. Dengan menggunakan analisis rasio keuangan ini akan diperoleh berbagai informasi yang bermanfaat sehubungan dengan keadaan operasi dan kondisi keuangan, namun terdapat juga keterbatasan informasi yang membutuhkan kehati-hatian.

Penelitian ini menganalisis perbedaan kinerja keuangan BTPN Syariah sebelum dan sesudah spinoff, dengan menggunakan rasio keuangan seperti berikut:

\section{Rasio CAR}

Adalah rasio yang menunjukkan kemampuan bank dalam menyediakan dana atau modal untuk keperluan pengembangan usaha dan menanggung risiko kerugian dana yang disebabkan oleh aktivitas operasional bank.

\section{Rasio NPF}

Rasio NPF merupakan indikator untuk menilai tentang tingkat pengembalian pembiayaan yang diberikan deposan kepada bank apakah kategori bermasalah atau tidak. Semakin tinggi rasio ini menunjukkan semakin banyak pembiayaan yang dikucurkan adalah bermasalah dan sebaliknya semakin kecil rasio ini berarti semakin selektif bank dalam memberikan pembiayaan.

\section{Rasio FDR}

Rasio FDR adalah tingkat kemampuan bank dalam menyalurkan dana pihak ketiga yang dihimpun oleh bank yang bersangkutan.

\section{Rasio BOPO}

Rasio biaya operasional terhadap pendapatan operasional (BOPO) merupakan rasio antara beban dengan pendapatan operasional yang dimaksudkan untuk menilai efisiensi dan efektivitas biaya operasional bank.

\section{Rasio ROA}

ROA merupakan rasio antara laba sesudah pajak terhadap total aset. ROA merupakan indikator profitabilitas perusahaan. Semakin tinggi tingkat laba maka akan semakin tinggi pula ROA-nya, karena hasil pengembalian terhadap jumlah harta serta dapat dipergunakan untuk mengukur efektivitas perusahaan dalam memanfaatkan seluruh sumberdaya yang ada dalam perusahaan. 
Sesuai dengan tujuan penelitian dan kajian pustaka yang sudah dibahas maka untuk memberikan gambaran yang jelas dan sistematis berikut kerangka pemikiran dijelaskan pada gambar 2.1

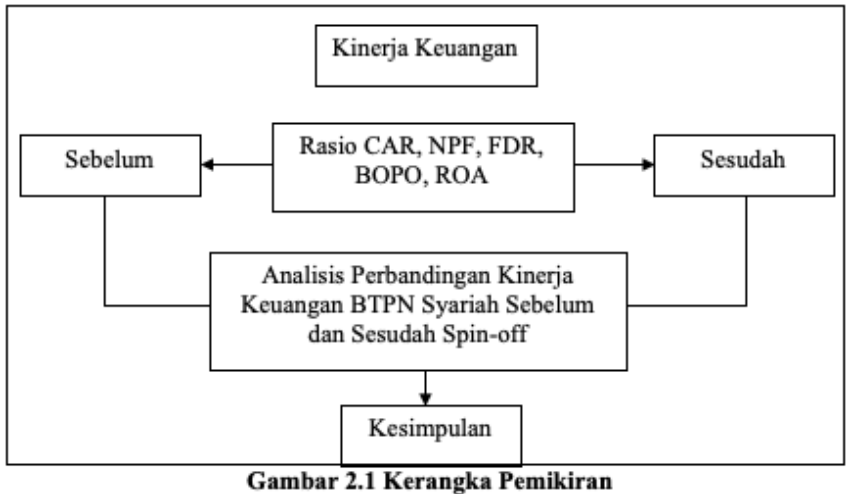

\section{Metode Penelitian}

\section{Sampel da Data}

Sampel dalam penelitian ini adalah Bank BTPN Syariah. Penelitian ini menggunakan sumber data sekunder. Data yang dikumpulkan berupa Laporan Keuangan Triwulanan BTPN Syariah yang berjumlah 30 triwulan, dimulai dari triwulan 1 tahun 2011 sampai dengan triwulan 3 tahun 2014 untuk data sebelum spin-off dan Laporan Keuangan triwulan 4 tahun 2014 sampai dengan triwulan 2 tahun 2018 untuk data sesudah spin-off.

\section{Metode Analisis Data dan Rancangan Pengujian}

Pada penelitian kali ini, untuk metode analisis data yang dipakai ada dua, pertama ialah uji normalitas dengan Kolmogorov-Smirnov serta melakukan uji beda menggunakan Sample T-Test.

\section{Metode Analisis Data}

Uji normalitas menggunakan SPSS versi 25 agar dapat mengetahui data yang akan diolah apa sudah terdistribusi dengan normal yang disebut dengan parametrik ataukah non parametrik yaitu datanya terdistribusi tidak normal.

Jika signifikan $>\alpha$ artinya terdistribusi normal Jika signifikan $<\alpha$ artinya tak terdistribusi normal Dimana $\alpha$ ialah $5 \%$ atau 0,05 .

\section{Uji Paired Sample T-Test}

Uji paired sample t-test pada penelitian ini digunakan untuk membuktikan hipotesis yang telah dirumuskan yaitu dengan membandingkan rasio CAR,
NPF, FDR, BOPO dan ROA BTPN Syariah sebelum dan sesudah melakukan pemisahan (spin-off), apakah setelah dianalisa terdapat perbedaan. Dengan tingkat keyakinan yang digunakan dalam pengujian (tingkat kepercayaan $95 \%$ atau $\alpha=5 \%$ )

\section{Rancangan Pengujian Hipotesis}

Uji hipotesis pada penelitian ini menggunakan uji paired sample t-test untuk melihat apakah terdapat perbedaan rata-rata antara sebelum dan sesudah dilakukan spin-off pada BTPN Syariah.

Langkah-langkah yang dilakukan untuk melakukan pengujian hipotesis adalah sebagai berikut:

1. Merumuskan Hipotesis Nol $(\mathrm{H} 0)$ dan Hipotesis Alternatif $(\mathrm{Ha})$

$\mathrm{H} 0: \mu_{1}=\mu_{2}$ (tidak ada perbedaan rasio CAR, NPF, FDR, BOPO dan ROA sebelum dan sesudah spin-off)

$\mathrm{H}_{\mathrm{a}}: \mu_{1} \neq \mu_{2}$ (ada perbedaan rasio CAR, NPF, FDR, BOPO dan ROA sebelum dan sesudah spin-off)

2. Melakukan uji Normalitas

3. Melakukan uji paired sample t-test

4. Menentukan kriteria penerimaan dan penolakan hipotesis sebagai berikut:

Jika nilai probabilitas > nilai $\alpha=5 \%$ maka $\mathrm{H} 0$ diterima ( $\mathrm{Ha}$ ditolak), artinya tidak terdapat perbedaan secara signifikan.

Jika nilai probabilitas < nilai $\alpha=5 \%$ maka $\mathrm{H} 0$ ditolak ( $\mathrm{Ha}$ diterima), artinya terdapat perbedaan secara signifikan.

\section{Hasil Penelitian}

\section{Gambaran Umum Penelitian}

Dibentuk melalui proses konversi dan spin-off pada 14 Juli 2014, Bank BTPN Syariah menjadi satusatunya bank di Indonesia yang fokus mengumpulkan dana dari keluarga dan kelompok sejahtera dan menyalurkannya kepada keluarga prasejahtera produktif sebagai bentuk pemberdayaan yang telah dilakukan sejak 2010 di Unit Usaha Syariah BTPN.

\section{Hasil Pengujian dan Analisis Data Hasil Uji Normalitas}


Tabel 4.1

Hasil Uji Normalitas One-Sample Kolmogorov-Smirnov Test Rasio Sebelum Spin-off

\begin{tabular}{|c|c|c|c|c|c|c|}
\hline & & $\begin{array}{c}\text { CAR } \\
\text { SEBELUM } \\
\end{array}$ & $\begin{array}{c}\text { NPF } \\
\text { SEBELUM }\end{array}$ & $\begin{array}{c}\text { FDR } \\
\text { SEBELUM }\end{array}$ & $\begin{array}{c}\text { BOPO } \\
\text { SEBELUM } \\
\end{array}$ & $\begin{array}{c}\text { ROA } \\
\text { SEBELUM } \\
\end{array}$ \\
\hline \multicolumn{2}{|l|}{$\mathrm{N}$} & 15 & 15 & 15 & 15 & 15 \\
\hline \multirow{2}{*}{$\begin{array}{l}\text { Normal } \\
\text { Parameters }\end{array}$} & Mean & 22.2607 & .7560 & 89.8153 & 75.6913 & 4.4327 \\
\hline & \begin{tabular}{|l} 
Std. \\
Deviation
\end{tabular} & 1.04684 & .13265 & 3.87691 & 2.48112 & .36745 \\
\hline \multirow{3}{*}{\begin{tabular}{|l} 
Most \\
Extreme \\
Differences \\
\end{tabular}} & Absolute & .119 & .215 & .183 & .199 & .167 \\
\hline & Positive & .101 & .215 & .183 & .199 & .140 \\
\hline & Negative & -.119 & -.094 & -.112 & -.115 & -.167 \\
\hline \multicolumn{2}{|l|}{ Test Statistic } & .119 & .215 & .183 & .199 & .167 \\
\hline \multicolumn{2}{|c|}{ Asymp. Sig. (2-tailed) } & .200 & .061 & .192 & .113 & .200 \\
\hline
\end{tabular}

Setelah melihat hasil di tabel di atas dan kita mendapatkan hasil dari uji K-S untuk semua rasio sebelum spin-off dan ditunjukkan bahwa hasil pengolahandata sudah terdistribusi normalsebab nilai untuk uji K-S lebih besar dari 0,05 dimana nilai K-S untuk rasio CAR $0.2 \%$, NPF $0.61 \%$, FDR $0.192 \%$, BOPO $0.113 \%$, dan ROA 0,2\%. Besaran nilai hasil uji K-S lebih besar dari 0,05 bermakna bahwa data tersebut telah berdistribusi dengan normal

Tabel 4.2

Hasil Uji Normalitas One-Sample Kolmogorov-Smirnov Test Rasio Setelah Spin-off

\begin{tabular}{|c|c|c|c|c|c|c|}
\hline & & $\begin{array}{c}\text { CAR } \\
\text { SESUDAH }\end{array}$ & $\begin{array}{c}\text { NPF } \\
\text { SESUDAH } \\
\end{array}$ & \begin{tabular}{c|} 
FDR \\
SESUDAH
\end{tabular} & $\begin{array}{c}\text { BOPO } \\
\text { SESUDAH }\end{array}$ & $\begin{array}{c}\text { ROA } \\
\text { SESUDAH }\end{array}$ \\
\hline $\mathrm{N}$ & & 15 & 15 & 15 & 15 & 15 \\
\hline Normal & Mean & 25.7800 & 1.4860 & 93.7427 & 77.3613 & 8.0567 \\
\hline Parameters $^{\mathrm{a}, \mathrm{b}}$ & $\begin{array}{l}\text { Std. } \\
\text { Deviation }\end{array}$ & 4.98906 & .22633 & 2.91198 & 9.08950 & 3.15931 \\
\hline Most & Absolute & .182 & .232 & .131 & .157 & .147 \\
\hline Extreme & Positive & .182 & .194 & .107 & .123 & .147 \\
\hline Differences & Negative & -.120 & -.232 & -.131 & -.157 & -.128 \\
\hline Test Statistic & & .182 & .232 & .131 & .157 & .147 \\
\hline Asymp. Sig. ( & (2-tailed) & .196 & .029 & .200 & .200 & .200 \\
\hline
\end{tabular}

Setelah melihat hasil di tabel sebelumnya, dan kita mendapatkan hasil dari uji K-S untuk semua rasio setelah spin-off dan ditunjukkan bahwa hasil pengolahan data sudah terdistribusi normal sebab nilai untuk Uji K-S lebih besar dari 0,05 dimana nilai K-S untuk rasio CAR $0.196 \%$, NPF $0.29 \%$, FDR $0.2 \%$, BOPO $0.2 \%$, dan ROA $0,2 \%$. Besaran nilai hasil uji K-S lebih besar dari 0,05 bermakna bahwadata tersebut telah berdistribusi dengan normall.

Sebab semua hasil uji K-S "KolmogorovSmirnov" telah menyatakan bahwa hasil pengolahandata telah berdistribusi normal, untuk itu uji yang dilakukan ialah uji Paired T-Test.

\section{Hasil Uji Paired T-Test Hasil Uji CAR}

Tabel 4.3

Hasil Uji Paired Sample T-Test Statistics CAR

\begin{tabular}{|c|l|c|c|c|c|}
\hline \multicolumn{2}{|c|}{} & Mean & $\mathrm{N}$ & $\begin{array}{c}\text { Std. } \\
\text { Deviation }\end{array}$ & $\begin{array}{c}\text { Std. Error } \\
\text { Mean }\end{array}$ \\
\hline \multirow{4}{*}{ Pair 1 } & $\begin{array}{l}\text { CAR } \\
\text { SEBELUM }\end{array}$ & 22.2607 & 15 & 1.04684 & .27029 \\
\cline { 2 - 6 } & $\begin{array}{l}\text { CAR } \\
\text { SESUDAH }\end{array}$ & 25.7820 & 15 & 4.98655 & 1.28752 \\
\hline
\end{tabular}

Berdasar table 4.3 menunjukkan hasil rasio CAR sebelum pemisahan ialah 22,2607\%, dan untuk rasio CAR sesudah pemisahan ialah $25,78 \%$. Yang dapat disimpulkan dari hasil tadi ialah dilihat rata-rata untuk CAR sebelum pemisahan telah naik sebesar 3,5193\% sesudah dilakukan pemisahan.

Tabel 4.4

Hasil Uji Paired Samples Test CAR

\begin{tabular}{|l|l|c|c|c|}
\hline & & $\mathrm{t}$ & $\mathrm{df}$ & $\begin{array}{l}\text { Sig. (2- } \\
\text { tailed) }\end{array}$ \\
\hline Pair 1 & $\begin{array}{l}\text { CAR SEBELUM-CAR } \\
\text { SESUDAH }\end{array}$ & -2.948 & 14 & .011 \\
\hline
\end{tabular}

Berdasarkan table 4.4 tersebut,, pada bagian

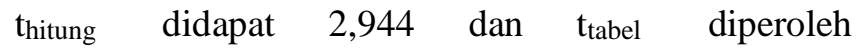
$=\operatorname{tinv}(\alpha ;$ df $) 2,145$. Sebab $t_{\text {hitung }}>t_{\text {tabel }}$, dengan kata lain $p$-value(sig)nya ialah $0,011<5 \%$, artinya $\mathrm{H}_{0}$ tidak diterima dan $\mathrm{H}_{\mathrm{a}}$ diterima dengan kata lain terdapat beda antar rasio CAR sebelum dan sesudah pemisahan.

\section{Hasil Uji NPF}

Tabel 4.5

Hasil Uji Paired Sample T-Test Statistics NPF

\begin{tabular}{|c|c|c|c|c|c|}
\hline & & Mean & $\mathrm{N}$ & $\begin{array}{c}\text { Std. } \\
\text { Deviation }\end{array}$ & $\begin{array}{l}\text { Std. Error } \\
\text { Mean }\end{array}$ \\
\hline & \begin{tabular}{|l} 
VPF \\
SEBELUM
\end{tabular} & .7560 & 15 & .13265 & .03425 \\
\hline Pair 1 & \begin{tabular}{|l|} 
NPF \\
SESUDAH
\end{tabular} & 1.4860 & 15 & .22633 & .05844 \\
\hline
\end{tabular}

Berdasar table 4.5 menunjukkan hasil rasio NPF sebelum pemisahan ialah $0.7560 \%$, dan untuk rasio NPF sesudah pemisahan ialah $1,4860 \%$. Yang dapat disimpulkan dari hasil tadi ialah dilihat rata-rata untuk NPF sebelum pemisahan telah naik sebesar $0,73 \%$ sesudah dilakukan pemisahan. 
Tabel 4.6

Hasil Uji Paired Samples Test NPF

\begin{tabular}{|l|l|c|c|c}
\hline & & $\mathrm{t}$ & $\mathrm{df}$ & $\begin{array}{c}\text { Sig. (2. } \\
\text { tailed) }\end{array}$ \\
\hline Pair 1 & $\begin{array}{l}\text { NPF SEBELUM - } \\
\text { NPF SESUDAH }\end{array}$ & -10.800 & 14 & .000 \\
\hline
\end{tabular}

Berdasarkan table 4.6 tersebut, pada bagian thitung didapat 10,800 dan tabel diperoleh $=\operatorname{tinv}(\alpha ;$ df $) 2,145$. Sebab thitung $>t_{\text {tabel }}$, dengan kata lain $p$-value $(\mathrm{sig})$ nya ialah $0.011<5 \%$, artinya $\mathrm{H} 0$ tidak diterima dan $\mathrm{Ha}$ diterima dengan kata lain terdapat beda antar rasio NPF sebelum dan sesudah pemisahan

\section{Hasil Uji FDR}

Tabel 4.7

Hasil Uji Paired Sample T-Test Statistics FDR

\begin{tabular}{|c|l|c|c|c|c|}
\hline \multicolumn{2}{|c|}{} & Mean & N & $\begin{array}{c}\text { Std. } \\
\text { Deviation }\end{array}$ & $\begin{array}{c}\text { Std. Error } \\
\text { Mean }\end{array}$ \\
\hline \multirow{2}{*}{ Pair 1 } & $\begin{array}{l}\text { FDR } \\
\text { SEBELUM }\end{array}$ & 89.8153 & 15 & 3.87691 & 1.00101 \\
\cline { 2 - 6 } & $\begin{array}{l}\text { FDR } \\
\text { SESUDAH }\end{array}$ & 94.4093 & 15 & 2.15132 & .55547 \\
\hline
\end{tabular}

Berdasar table 4.7 menunjukkan hasil rasio FDR sebelum pemisahan ialah $89,8153 \%$, dan untuk rasio FDR sesudah pemisahan ialah 93,7427\%. Yang dapat disimpulkan dari hasil tadi ialah dilihat rata-rata untuk FDR sebelum pemisahan telah naik sebesar 3,9274\% sesudah dilakukan pemisahan.

Tabel 4.8

Hasil Uji Paired Samples Test FDR

\begin{tabular}{|l|l|c|c|c}
\hline & & $\mathrm{t}$ & $\mathrm{df}$ & $\begin{array}{c}\text { Sig. (2. } \\
\text { tailed) }\end{array}$ \\
\hline Pair 1 & $\begin{array}{l}\text { FDR SEBELUM - } \\
\text { FDR SESUDAH }\end{array}$ & -3.917 & 14 & .002 \\
\hline
\end{tabular}

Berdasarkan table 4.8 tersebut, pada bagian


$=\operatorname{tinv}(\alpha ; \mathrm{df}) 2,145$. Sebab $t_{\text {hitung }}>\mathrm{t}_{\text {tabel }}$, dengan kata lain $p$-value (sig) nya ialah $0,004<5 \%$, artinya $\mathrm{H}_{0}$ tidak diterima dan $\mathrm{H}_{\mathrm{a}}$ diterima dengan kata lain terdapat beda antar rasio FDR sebelum dan sesudah pemisahan.

\section{Hasil Uji BOPO}

Tabel 4.9

Hasil Uji Paired Sample T-Test Statistics BOPO

\begin{tabular}{|c|l|c|c|c|c|}
\hline \multicolumn{2}{|c|}{} & Mean & N & $\begin{array}{c}\text { Std. } \\
\text { Deviation }\end{array}$ & $\begin{array}{c}\text { Std. Error } \\
\text { Mean }\end{array}$ \\
\hline \multirow{2}{*}{ Pair 1 } & $\begin{array}{l}\text { BOPO } \\
\text { SEBELUM }\end{array}$ & 75.6913 & 15 & 2.48112 & .64062 \\
\cline { 2 - 6 } & $\begin{array}{l}\text { BOPO } \\
\text { SESUDAH }\end{array}$ & 77.3613 & 15 & .908950 & 2.34690 \\
\hline
\end{tabular}

Berdasar table 4.9 menunjukkan hasil rasio BOPO sebelum pemisahan ialah 75,6913\%, dan untuk rasio BOPO sesudah pemisahan ialah $77,3613 \%$. Yang dapat disimpulkan dari hasil tadi ialah dilihat rata-rata untuk rasio BOPO sebelum pemisahan telah naik sebesar $1,67 \%$ sesudah dilakukan pemisahan.

Tabel 4.10

Hasil Uji Paired Samples Test BOPO

\begin{tabular}{|l|l|c|c|c|}
\hline & & $\mathrm{t}$ & $\mathrm{df}$ & $\begin{array}{c}\text { Sig. (2- } \\
\text { tailed) }\end{array}$ \\
\hline Pair 1 & $\begin{array}{l}\text { BOPO SEBELUM- } \\
\text { BOPO SESUDAH }\end{array}$ & -.665 & 14 & .517 \\
\hline
\end{tabular}

Berdasarkan table 4.10 tersebut,, pada bagian $t_{\text {hitung didapat } 0,665 \text { dan }} t_{\text {tabel }}$ diperoleh $=\operatorname{tinv}(\alpha ; d f) 2,145$. Sebab thitung $>t_{\text {tabel }}$, dengan kata lain $p$-value (sig) nya ialah $0,517<5 \%$, artinya $\mathrm{H}_{0}$ tidak diterima dan $\mathrm{H}_{\mathrm{a}}$ diterima dengan kata lain terdapat beda antar rasio BOPO sebelum dan sesudah pemisahan.

\section{Hasil Uji ROA}

Tabel 4.11

Hasil Uji Paired Sample T-Test Statistics ROA

\begin{tabular}{|c|l|c|c|c|c|}
\hline \multicolumn{2}{|c|}{} & Mean & $\mathrm{N}$ & $\begin{array}{c}\text { Std. } \\
\text { Deviation }\end{array}$ & $\begin{array}{c}\text { Std. Error } \\
\text { Mean }\end{array}$ \\
\hline \multirow{4}{*}{ Pair 1 } & $\begin{array}{l}\text { ROA } \\
\text { SEBELUM }\end{array}$ & 4.4327 & 15 & .36745 & .09488 \\
\cline { 2 - 6 } & $\begin{array}{l}\text { ROA } \\
\text { SESUDAH }\end{array}$ & 8.0567 & 15 & 3.15931 & .81573 \\
\hline
\end{tabular}

Berdasar table 4.11 menunjukkan hasil rasio ROA sebelum pemisahan ialah $4.4327 \%$, dan untuk rasio ROA sesudah pemisahan ialah $8,0567 \%$. Yang dapat disimpulkan dari hasil tadi ialah dilihat rata-rata untuk ROA sebelum pemisahan telah naik sebesar 3,624\% sesudah dilakukan pemisahan. 
Tabel 4.12

Hasil Uji Paired Samples Test ROA

\begin{tabular}{|l|l|c|c|c}
\hline & & $\mathrm{t}$ & $\mathrm{df}$ & $\begin{array}{c}\text { Sig. (2. } \\
\text { tailed) }\end{array}$ \\
\hline Pair 1 & $\begin{array}{l}\text { ROA SEBELUM - } \\
\text { ROA SESUDAH }\end{array}$ & -4.310 & 14 & .001 \\
\hline
\end{tabular}

Berdasarkan table 4.12 tersebut,, pada bagian thitung didapat 4,310 dan tabel diperoleh $=\operatorname{tinv}(\alpha ; \mathrm{df}) 2,145$. Sebab thitung $>$ ttabel, dengan kata lain $p$-value (sig) nya ialah $0.011<$ $5 \%$, artinya $\mathrm{H} 0$ tidak diterima dan $\mathrm{Ha}$ diterima dengan kata lain terdapat beda antar rasio CAR sebelum dan sesudah pemisahan.

\section{Pembahasan Hasil Analisis Data Perbandingan Rasio CAR}

Berdasarkan hasil uji penelitian pada rasio CAR menggunakan uji beda diperoleh nilai signifikansi rasio CAR ialah $0.011>$ dari $\alpha$ 5\% atau 0,05 . Ini artinya benar terdapat perbedaan pada rasio CAR sebelum dan setelah BTPNS membuat pemisahan. Tentunya hasil penelitian ini sesuai dengan Utami dan Chotib (2014) benar ada perbedaan antara CAR sesudah spin-off.

Menurut Bank Indonesia, skor kredit standar rasiio CAR minimum ialah $8 \%$ dan makin naik akan makin bagus. Jika dilihat dari rerata rasio CAR sebelum dan setelah pemisahan meningkat 3,5193\%. Peningkatan tersebut permodalnya membaik.

\section{Perbandingan Rasio NPF}

Berdasarkan hasil uji hipotesis penelitian pada rasio NPF menggunakan uji beda uji Paired T-Test, di dapat bahwa rasio NPF nilai signifikansi sebesar 0.000 lebih kecil dari $\alpha(5 \%)$. Sehingga menunjukkan benar terdapat perbedaan pada rasio NPF Gross sebelum dan sesudah pemisahan (spin-off). Hasil penelitian ini sejalan dengan penelitian yang dilakukan oleh Anggraini, Yuliani dan Umrie (2017) yang menemukan perbedaan rasio NPF sesudah spin-off.

Menurut SE BI No. 9/24/DPbS tahun 2007, pertumbuhan rasio NPF terbaik ialah kurang dari sama dengan $2 \%$. Jika dilihat dari perkembangan rasio NPF Bank BTPN Syariah sebelum spin-off adalah 0,756\% dan meningkat setelah spin-off menjadi $1,486 \%$. Terdapat perbedaan selisih $0.73 \%$ yang berarti nilai rasio NPF memburuk

\section{Perbandingan Rasio FDR}

Berdasarkan hasil uji penelitian pada rasio FDR menunjukkan hasil hipotesis menggunakan uji statistik parametrik dengan uji Paired, di dapat bahwa nilai signifikansi rasio FDR sebesar 0.004 lebih kecil dari $\alpha(5 \%)$. Sehingga menunjukkan bahwa benar terdapat perbedaan pada rasio FDR sebelum dan sesudah pemisahan (spin-off).

Menurut Biro Riset Infobank, standar terbaik rasio FDR ialah $78 \%$ sampai dengan di atas $100 \%$ untuk Bank Umum Syariah. Dapat dilihat pada rerata rasio FDR sebelumnya ialah $89,8153 \%$ dan meningkat $3,9274 \%$ menjadi $93,7427 \%$ setelah spin-off. Peningkatan rasio FDR berarti positif bahwa kinerja keuangan BANK BTPNS yang dinilai dengan rasiio FDR makin membaik sesudah spin-off.

\section{Perbandingan Rasio BOPO}

Berdasarkan hasil uji penelitian pada rasio BOPO menunjukkan hasil hipotesis menggunakan uji statistik parametrik dengan uji beda Paired T-test, di dapat bahwa pada rasio BOPO nilai signifikansi sebesar 0.517 lebih besar dari $\alpha$ sebesar $5 \%(0,05)$. Hal ini menunjukkan bahwa tidak terdapat perbedaan pada rasio BOPO sebelum dan sesudah spin-off.

Berdasarkan hasil hitung rata-rata nilai rasio BOPO sebelum spin-off adalah 75,6913\% yaitu < jika ingin dibandingkan dengan nilai rasio BOPO setelah pemisahan ialah 77,3613\%. kenaikan sebesar $1,67 \%$ yang berarti nilai rasio BOPO sesudah pemisahan adalah $1,67 \%$ lebih buruk karena semakin tinggi nilai rasio ini maka bank tersebut secara keseluruhan semakin tidak efisien. Hal ini dapat dikarenakan biaya operasional bank tidak mampu memenuhi pendapatan operasionalnya sehingga menjadikan bank tidak dapat memperoleh laba dan kegiatan operasional bank Syariah tidak lancar.

\section{Perbandingan Rasio ROA}

Berdasarkan hasil uji penelitian pada rasio ROA menunjukkan hasil hipotesis menggunakan uji statistik parametrik dengan uji Paired T-Test, di dapat bahwa rasio ROA nilai signifikansi sebesar 0.001 lebih kecil dari $\alpha(5 \%)$. Sehingga menunjukkan benar terdapat perbedaan pada rasio ROA sebelum dan sesudah spin-off. 
Menurut Biro Riset Infobank, standar terbaik rasio ROA adalah diatas $1,5 \%$. Berdasarkan hasil itung rerataa rasio ROA sebelum pemisahan didapat angka $4,4327 \%$ dan setelah pemisahan ialah $8.0567 \%$. dengan demikian artinya terdapat peningkatan rasio ROA sebesar 3,624\%. Peningkatan pada rasio ROA berarti positif bahwa kinerja keuangannya Bank BTPNS yang dinilai menggunakan ROA semakin membaik sesudah spinoff.

\section{Kesimpulan, Keterbatasan dan Saran}

\section{Kesimpulan}

Penelitian ini memiliki tajuk tentang "Analisis Perbandingan Kinerja Keuangan pada Bank Umum Syariah Sebelum dan Sesudah Melakukan Spin-of (Studi pada Bank BTPN Syariah)". Dalam meneliti, penulis menggunakan Uji Normalitas dan Uji Beda Paired-SampleT-Test dengan memakai aplikasi SPSS version 25. Data yang diolah berupa rasio yang didapat dari laporan keuangan kuartal 12011 sampai dengan kuartal 32018.

Setelah melakukan perhitungan, maka penulis telah menarik kesimpulan seperti ini:

1) Perbandingan kiinerja keuangan yang dinilai dari rasio CAR pada Bank BTPN Syariah menunjukkan $\mathrm{H} 0$ tidak diterima dan Ha diterima, berarti ada beda rasio CAR sebelum dan setelahnya

2) Perbandingan kiinerja keuangan yang dinilai dari rasio NPF pada Bank BTPN Syariah menunjukkan H0 tidak diterima dan Ha diterima, berarti ada beda rasio NPF sebelum dan setelahnya

3) Perbandingan kiinerja keuangan yang dinilai dari rasio FDR pada Bank BTPN Syariah menunjukkan $\mathrm{H} 0$ tidak diterima dan $\mathrm{Ha}$ diterima, berarti ada beda rasio FDR sebelum dan setelahnya

4) Perbandingan kiinerja keuangan yang dinilai pada rasio BOPO pada Bank BTPN Syariah menunjukkan $\mathrm{H} 0$ diakui dan $\mathrm{Ha}$ tak diterima, berarti tak ada beda di rasio BOPO sebelum dan setelahnya

5) Perbandingan kiinerja keuangan yang dinilai dari rasio ROA pada Bank BTPN Syariah menunjukkan $\mathrm{HO}$ tidak diterima dan $\mathrm{Ha}$ diterima, berarti ada beda rasio ROA sebelum dan setelahnya

\section{Keterbatasan penelitian}

Penelitian ini memiliki keterbatasan yang dapat dijadikan pertimbangan bagi penelitian selanjutnya. Penulis sangat menyadari bahwa penelitian ini memiliki kelemahan dan kekurangan yaitu periode pengamatan kurang luas, hanya dimulai dari triwulan 1 tahun 2011 (Maret 2011) sampai triwulan 3 tahun 2018 (Juni 2018) dikarenakan keterbatasan data yang dipublikasikan oleh Bank BTPN Syariah.

\section{Saran}

1) Bagi BTPNS

Berdasarkan hasil penelitian, ada dua rasio yang memburuk setelah spin-off yaitu rasio NPF dan rasio BOPO. Untuk meningkatkan lagi rasio NPF menjadi lebih baik, dapat dilakukan dengan cara memperbaiki pembiayaan-pembiayaan bermasalah yang ada. Bank sebaiknya harusnya memperkuat kinerja keuangannya serta memperbaiki operasionalnya.

2) Bagi Peneliti kedepan

Memungkinkan untuk menggunakan rasiio akuntansi lain yang tak ada di penelitin ini yang mungkin mempengaruhi kinerja keuangan bank dan melengkapi laporan keuangan yang masih terbatas dikarenakan kurang tersedianya data laporan keuangan publikasi bank.

\section{Daftar Pustaka}

Adnan, Ridwan, \& Fildzah. (2016). Pengaruh Ukuran Bank, Dana Pihak Ketiga, Capital Adequacy Ratio, dan Loan To Deposit Ratio Terhadap Penyaluran Kredit Pada Perusahaan Perbankan yang Terdaftar Di Bursa Efek Indonesia Tahun 2011-2015. Jurnal Dinamika Akuntansi Dan Bisnis, 3(2), 49-64.

Ahmad, R. (2012). Analisis Kinerja Keuangan Bank Rakyat Indonesia Dan Bank BRI syari'ah Di Indonesia Tahun 2009 - 2012.

Anggraini, R., Yuliani, \& Hs Umrie, R. (2017). Analisis Tingkat Kesehatan Bank Syariah Sebelum dan Sesudah Spin-Off. Ekspektra, Jurnal Manajemen Dan Bisnis2, 1(2017), 1120.

Bank Indonesia. (2007). Peraturan Bank Indonesia No.9/24/DPbS Perihal Sistem Penilaian Tingkat Kesehatan Bank Umum Berdasarkan Prinsip 
Syariah. Jakarta

Brigham, Eugene dan Houston, J.F. (2001). Manajemen Keuangan II. Jakarta: Salemba Empat.

Chotib, A., \& Utami, W. (2014). Studi Kinerja PT BNI Syariah Sesudah Pemisahan (Spin Off) dari PT Bank BNI (Persero) Tbk. Akuntabilitas, VII(2), 94-108.

Danupranata, G. (2013). Manajemen Bank Syariah, Jakarta: Salemba Empat.

Dendawijaya, L. (2009). Manajemen Perbankan. Jakarta: Ghalia Indonesia.

Fahmi, I. (2011). Analisis Laporan Keuangan. Lampulo: Alfabeta.

Harmono. (2011). Manajemen Keuangan Berbasis Balanced Scorecard. Jakarta: Bumi Aksara.

Inayah, N. (2016). Analisis Kinerja Keuangan Perusahaan Sebelum dan Sesudah Go Public. Jurnal Ilmiah Mahasiswa Fakultas Ekonomi Dan Bisnis Universitas Brawijaya, 1.

Infobank. (2018). Sharia Insight. Infobank, Vol. XL No. 4780, 84-85.

Iqbal, M. (2018). Kebijakan Office Channeling dan Spin Off Stimulan Perbankan Syariah. Jurnal Manajemen \& Bisnis Aliansi, (November), $37-44$.

Ismail. (2011). Perbankan Syariah, Jakarta: Prenadamedia Group.

James C, Van Horne dan John M, Wachowis. (2005). Prinsip-prinsip Manajemen, Jakarta : Salemba Empat.

Machmud, A \& Rukmana. (2010). Bank Syariah : Teori, Kebijakan, dan Studi Empiris di Indonesia, Jakarta: Erlangga.

Martono, N. (2010). Statistik Sosial: Teori dan Aplikasi Program SPSS. Yogyakarta: Gava Media

Nizar, A. (2015). Analisa Efisiensi Bank Umum Syariah Sebelum dan Setelah SpinOff, Skripsi Sarjana Fakultas Syariah dan Hukum.

Norfitriani, S. (2016). Analisis Efisiensi dan Produktivitas Bank Syariah di Indonesia Sebelum dan Sesudah SPIN OFF. Jurnal Ekonomi Syariah Indonesia, 2(Desember 2016), 134-143.

Perwataatmadja, K. A \& Tanjung, H. (2007). Bank Syariah Teori, Praktik, dan Peranannya.
Jakarta: Celestial Publishing.

Raharjo, H. (2009). Hukum Perusahaan. Yogyakarta: Pustaka Yustisia.

Rahmawaty, \& T, Andari Yudina. (2015). Pengaruh Return On Asset (ROA) dan Financing To Deposit Ratio (FDR) terhadap Tingkat Bagi Hasil Deposito Mudharabah pada Bank Umum Syariah. Jurnal Dinamika Akuntansi dan Bisnis, 2(1), 92-103.

Ramdani, A. (2015). Pengaruh Kebijakan Pemisahan Terhadap Laba Pada Bank Bni Syariah Etikonomi, 14(April), 17-34.

Rianto Al Arif, M. N. (2014). Spin-off and its impact on the third par ty funds of Indonesian Islamic banking industry. Economic Journal of Emerging Markets, 1(2014), 50-55.

Rianto Al Arif, M. N. (2015). The Effect Of Spin-Off Policy On Financing Growth In Indonesian Islamic Banking Industry. Al-Ulum, 15(1), 173184.

Riyadi, S. (2006). Banking Assets And Liability Management (Edisi Ketiga). Jakarta: Lembaga Penerbit Fakultas Ekonomi Universitas Indonesia.

Rohaya, H. (2016). Perkembangan Skala Usaha Perbankan Syariah di Indonesia Pra dan Pasca Kebijakan Office Channeling. La_Riba, 2(2), 191-213.

Ruky, M.S. (1999). Menilai Penyertaan dalam Perseroan. Jakarta: Gramedia Pustaka Utama.

Sekaran, U \& R, Bougie. (2013). Research Methods for Business. Edisi 6 Jakarta: Salemba Empat.

Sihombing, N. H., \& Yahya, M. R. (2016). Pengaruh Kebijakan Spin-Off, Beban Operasional Pendapatan Operasional (Bopo), Dana Pihak Ketiga (Dpk), dan Non Performing Financing (Npf) terhadap Profitabilitas Perbankan Syariah Di Indonesia. Jurnal Ilmiah Mahasiswa Ekonomi Akuntansi, 1(2), 127-137.

Sujarweni, V. Wiratna. (2015). Metodologi Penelitian Bisnis \& Ekonomi. Yogyakarta : Pustaka Baru Press.

Suliyono, J. (2010). 6 Hari Jago SPSS. Yogyakarta: Cakrawala.

Suryani \& Hendryadi. (2015). Metode Riset Kuantitatif: Teori Dan Aplikasi Pada 
Penelitian Bidang Manajemen Dan

Ekonomi Islam, Jakarta: Prenadamedia

Group.

Susilo. (2013). Bank dan Lembaga Keuangan Lainnya. Jakarta: Salemba. Empat.

Taswan. (2006). Manajemen Perbankan: Konsep, Teknik dan Aplikasi. Yogyakarta: UPP STIM YKPN.

Umam, K \& V, Antoni. (2015). Coorporate Action Pembentukan Bank Syariah (Akuisisi, Konversi, dan Spin-Off), Yogyakarta: Gadjah Mada University Press.

Wardani, S., \& Fitriati, R. (2010). Analisis Komparasi Profitabilitas Sebelum dan Sesudah Penawaran Umum Saham Perdana. Jurnal Ilmu Administrasi dan Organisasi, Vol. 17, No. 2, 90-100.

Yuliani. (2016). Manajemen Lembaga Keuangan. Palembang: Citrabooks Indonesia.

Yuniarti, U. ( 2011). Analisis Kinerja Keuangan dan Pengukuran Tingkat Kesehatan PT Bank BRI Periode 2007-2009 dengan Menggunakan Rasio Keuangan Bank dan Metode CAMELS. Jurnal Ekonomi dan Bisnis. Vol. 5, No. 2,2.

Otoritas Jasa Keuangan. (2018). Perkembangan Perbankan Syariah. Statistik Perbankan Syariah. https://www.ojk.go.id/id/kanal/syariah/datadan- statistik/statistik-perbankansyariah/Documents/Pages/Statistik-PerbankanSyariah---November2018/SPS\%20November\%202018.pdf (Diakses pada 13 Maret 2019)

Otoritas Jasa Keuangan. (2019). Memacu Pertumbuhan dan Menjawab Tantangan Sektor Jasa Keuangan, Kini dan Nanti. Master Plan Sektor Jasa Keuangan Indonesia Periode 2015-2019.

https://www.ojk.go.id/id/berita-dankegiatan/publikasi/Documents/Pages/Masterplan-sektor-jasa-keuangan-indonesia-periode2015-

2019/MPSJKI\%20OJK\%20Final_Ind.pdf(Diak ses pada 13 Maret 2019)

https://www.btpnsyariah.com/id/ (Diakses pada 18 maret 2019) 